\title{
Crowdfunding and Internet Non-public Equity Financing Based on the Development Perspective of Combining Technology-Based SMEs
}

\author{
Yuanyuan Huang \\ Shanghai Academy, Shanghai University, No.149, Yanchang Road, Shanghai, China \\ huangyuanyuan3286@163.com
}

Keywords: Supply-side Reform; Internet Finance; SMEs Financing; Equity Crowdfunding

\begin{abstract}
In order to promote supply and demand balance and enhance economic vitality and resilience, equity crowdfunding is of great significance to supporting the financing of SMEs, promoting economic restructuring and the development of power conversion. However, at present, China's credit base and institutional environment are difficult to meet the needs of large-scale development of equity crowdfunding. In view of the inconsistency of imbalance, we must proceed from many aspects to achieve high-quality development. This paper proposes the development ideas and related regulatory proposal for equity crowdfunding.
\end{abstract}

\section{Introduction}

The 2018 Central Economic Work Conference reviewed the development of the party since the 18th National Congress. China's, economy in China has grown at an average annual rate of $7.1 \%$, and its economic strength has continuously increased. This has laid a solid foundation for reform and development in other areas and has also provided strong impetus for world economic growth. With the development of the economy, China's economic structure has begun to undergo major changes. In order to promote supply and demand balance and enhance economic vitality and resilience, it is still necessary to continue to promote supply-side structural reforms and economic system reforms.

In March 2018, the China Securities Regulatory Commission issued the 2018 annual legislative work plan, "Measures for the Administration of Equity Crowdfunding Pilot Projects." was listed as the first of the 15 projects of the CSRC's "Strive to introduce the key projects during the year." The "Guiding Opinions on Accelerating the Innovation of Science and Technology and Developing the Service Industry of Science and Technology in Beijing" issued in January 2018 has also released favorable signals for the development of new technology finance models such as equity crowdfunding.

\section{Development Status of Crowdfunding Platform in China}

In 2018, the number of operating crowdfunding platform continued to reduce in China, but the overall financing scale of the industry is still rising, and platforms with no background or strength are gradually being phased out. As of the end of April 2018, there were 258 crowdfunding platforms in operation in China. In April, a total of 14 platforms failed to launch or link, 3 platforms were transformed, and 1 new platform was added. Among the platforms in operation, there are 82 rights-based platforms, 79 non-public equity financing (hereinafter referred to as "equity-based") platforms, 48 property-based platforms, 36 integrated platforms, and 13 public-welfare platforms [1].

For non-public equity financing, it began to decline in May 2017, and it bottomed out in September 2017. By the end of November, the number of successful projects reached 42. This was the highest value since May 2017, and the number of projects decreased slightly in December. Since then, the number of successful projects has risen sharply for three consecutive months, and the number of successful projects has declined slightly to 58 in April 2018 [2].

In addition, as mentioned in the report of the Nineteenth Congress, at present, the major contradictions in our country's society have turned into a contradiction between the people's 
ever-growing needs for a better life and unbalanced development. In view of the inconsistency of imbalance, we must proceed from many aspects such as economic construction, cultural construction, rule of law, and ecological environment construction to achieve high-quality development. The report also emphasized that accelerating the development of advanced manufacturing industries and promoting the deep integration of the Internet, big data, artificial intelligence and the real economy, nurturing in the areas of high-end consumption, innovation and leadership, green and low-carbon, shared economy, modern supply chain, and human capital services. New growth points and new momentum.

Since 2008, crowdfunding platforms such as Indiegogo, Kickstarter and AngelList have been established in the United States. As of May 2018, the total financing of the US Kickstarter platform, the largest crowdfunding platform in the United States, reached US\$3,699,099,879. There were 144,429 successful financing projects with a total investment of 14,692,394. people. In 2011, crowdfunding began to rise in China. In 2013, the first case of equity crowdfunding in China was successfully raised. In 2014, the first secured equity crowdfunding project took place in China. At the same time, the normative exploration of the equity crowdfunding model is continuing.

\section{The Advantages of Equity Crowdfunding Financing Technology-based SMEs}

Financing Match Analysis Based on Financial Cycle Theory of SMEs. According to relevant data, China's SMEDI in the first quarter of 2018 was 93.2, continuing to rise slightly. It is expected that the environment for the survival and development of SMEs will remain severe[3], and the pressure on production and operation and the cost burden will remain large, and investment confidence will be insufficient.

In January 2018, the World Bank, the Small and Medium Business Finance Forum, and the International Finance Corporation jointly released the "Financial Micro-enterprise Financing Gaps: Assessment of Inadequate Financing and Opportunities for Micro, Small, and Medium-sized Firms in Emerging Markets," which reported that 56 million Chinese micro, SMEs had $41 \%$ of enterprises have credit difficulties, and the financing gap of domestic SMEs amounts to 1.9 trillion US dollars (equivalent to nearly 12 trillion yuan).

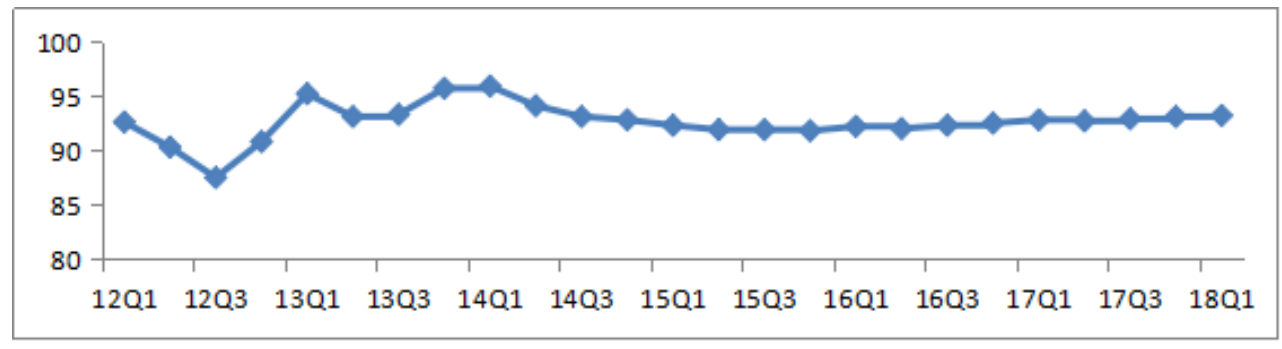

Figure 1. Finite China SME Development Index Operation Diagram

There is a Macmillan Gap (Macmillan Gap) problem among SMEs throughout the world, including China, that is, the suppliers of funds are not willing to provide funds on the conditions required by SMEs. From the perspective of SMEs' financial cycle theory, Allen N. Berger and Gregory F. Udell (1998)[4] believe that the financing needs and options of SMEs may change as the business grows in the financing growth cycle that SMEs may have. In the early stages of product or business concept development, where the company's assets were mostly intangible assets, the management system and financial information of SMEs was still incomplete, the information was not transparent enough, and the external financing resources available to them were few. Due to the lack of sufficient and effective collaterals and perfect credit records, the information asymmetry between the lenders and borrowers, as well as the lack of service capabilities of traditional financial institutions, has always been a costly and difficult problem for microfinance companies to obtain financing. 


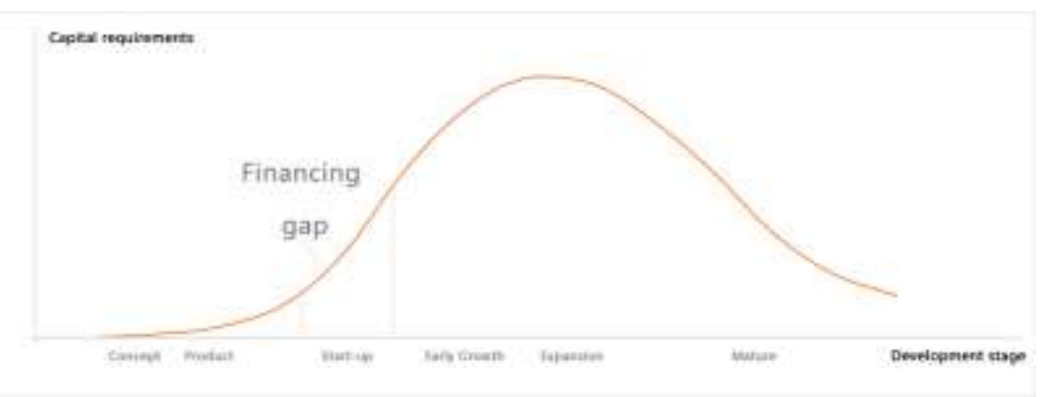

Figure 2. Finite Enterprise development stage and capital requirements

As China enters the new normal economy, the multi-level market system of China's capital market has also taken shape. It is mainly composed of main board, small and medium board, GEM board, new board, regional equity, but overall development is still immature. A considerable number of SMEs or start-ups cannot timely receive suitable external resources to meet their financing needs for further development. Therefore, the financing channels of SMEs need to be further smoothed, and the standardization of regional equity markets remains to be improved.

To further implement "mass entrepreneurship and innovation" at the real economy level and enhance the vitality of China's economic development, the role of small, medium, and large enterprises can not be underestimated, especially for entrepreneurial and technological small, medium and micro enterprises, which generally have light assets and high Input, high growth, high returns, and high risk characteristics [5].

As a sub-category of crowdfunding, equity crowdfunding mainly refers to the public small-equity financing through the Internet, and must be conducted through an equity crowdfunding financing intermediary agency platform (internet website or other similar electronic media). The characteristics of "open, small, and popular" possessed by equity crowdfunding also provide new solutions for diversifying entrepreneurial innovation risks, building multi-level capital markets, advancing popular entrepreneurship, and innovation.

Information Disclosure Analysis Based on "Lemon Market" Theory. The Market for Lemons was presented in the 1970 paper "The Lemon Market: Quality Uncertainty and Market Mechanism" by the 2001 Nobel Laureate in Economics, Acroft, under information asymmetry. [6]The defective market, the lemon market, has serious moral hazard and risk of adverse selection. In the science and technology loan market, there is a serious information asymmetry between banks and technology-based companies, especially technology-based SMEs, and there is a high cost to eliminate asymmetries. Banks tend to adopt high interest rate policies for all lenders that cannot identify credit risks. A group of technology-based SMEs that originally had good credit may therefore choose other lower-cost methods to withdraw from the science and technology loan market.

Xie Ping (2012) believes that under the Internet finance model, information processing and risk assessment are carried out in a networked manner, and the degree of market information asymmetry is very low; the cost of capital supply and demand on the capital match and risk sharing is very low and can be directly transaction. [7] Equity crowdfunding has the characteristics of "open, small, and public" and must pass the equity public The financing intermediary agency platform (internet website or other similar electronic media) is conducted to effectively improve the transparency of information from its own operating mechanism. When the project goes online, the financier needs to comply with relevant laws and regulations and the requirements of the crowdfunding platform, especially In terms of social public interests and economic and financial security, the project will be introduced in detail. The transparency of information disclosure will be enhanced from multiple dimensions, diversity, and adequacy, and the mutual understanding between the two parties will be deepened. After the project goes online, investors can help investors greatly increase the amount of information that can be grasped based on the number of supporters for the project on the platform, the content of the evaluation, and the use of platform's big data analysis to determine the feasibility and possible risks of the project. [8] 
In terms of government supervision, since 2015, China's supervision of Internet finance has become more stringent. On July 18, 2015, the Ten Ministries, including the People's Bank of China, jointly issued "Guiding Opinions on Promoting the Healthy Development of Internet Finance" put forward specific requirements for the standardized development of the Internet finance industry, and hope that relevant agencies will file records, carry out depository of funds in banks, disclose the status of financiers through the credit disclosure system, and strengthen the operating mechanism of the platform and financial credit information database. Business cooperation between credit bureaus and so on. The way to build a healthy ecosystem for the development of the crowdfunding industry is also conducive to the establishment of relevant data statistics and monitoring systems.[9]

Industrial agglomeration theory analysis of external environmental impact. As a new form of industrial space organization, industrial clusters have attracted wide attention from domestic and foreign scholars due to their strong competitive advantages. They have received increasing attention in the orientation and organization of urban planning industry development, especially in developing countries. area. In urban planning and urban research, industrial clusters mainly refer to the economic phenomena of SMEs as the main body, related enterprises, research institutions, industry associations, and government service organizations. In the cluster, the potential for industrial development in regions or cities is enhanced and overall industrial competitiveness is enhanced.[10]

In April 2018, the national crowdfunding platform successfully funded projects have been distributed in the area, the Beijing area topped the list, the amount of funds raised reached 1.031 billion yuan; followed by Zhejiang, has raised funds of 405 million yuan; Shanghai and Guangdong respectively. Ranked third and fourth, the amount of funds raised reached 292 million yuan and 284 million yuan respectively; Shandong ranked fifth, reaching 228 million yuan; Hunan ranked sixth, and the amount of funds raised reached 073 million yuan. The funds raised by the above six provinces and cities accounted for approximately $94.60 \%$ of the total funds raised in the country. The other 13 provinces and cities with crowdfunding platforms only raised funds of 132 million yuan, which accounted for $5.40 \%$ of the total amount of funds raised in the country, and the regional differences were more obvious.[11]

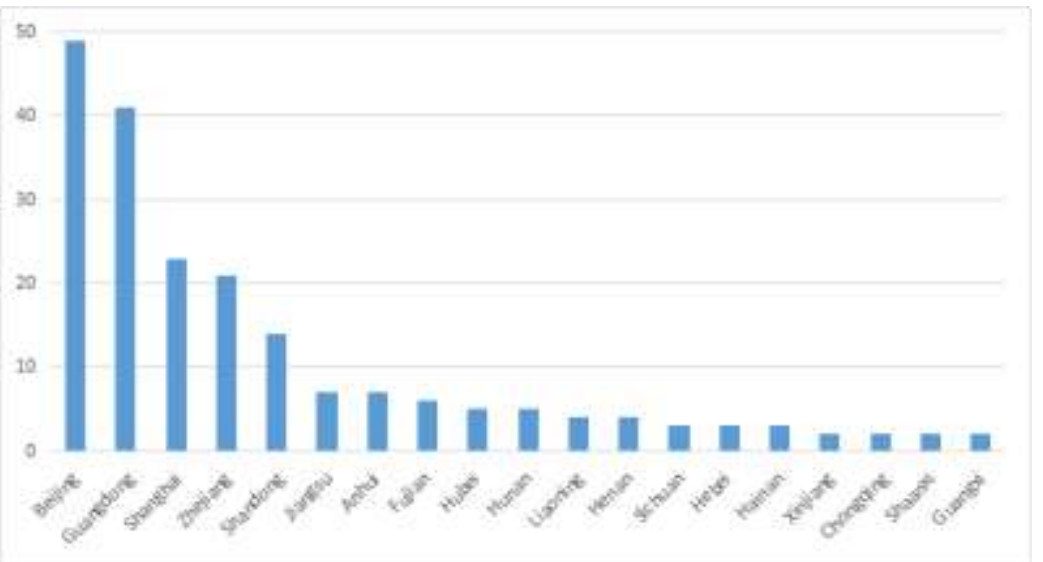

Figure 3. Finite Number of Normal Operating Platforms in Various Provinces in China from January to April

In addition, taking the Shanghai region as an example, In June 2015, Shanghai took the lead in launching an equity crowdfunding pilot to issue the first equity crowdfunding business license to ants who have not yet gone online. At the end of the year, the "Interim Measures for Shanghai Angel Investment Risk Compensation Management" was formulated, which stipulated that angel investment should be invested. In April 2016, the State Council issued a document to support the establishment of a special scientific and technological innovation section in the Shanghai Equity Trusteeship Exchange Center. This series of first-line policies has created a favorable environment and opportunities for the development of equity crowdfunding in Shanghai.

Shanghai is an area where the Internet crowdfunding business was launched earlier in the country, and it is at the forefront of equity crowdfunding innovation in the country, mainly reflected in two 
aspects: First, the government actively encourages the development of equity crowdfunding, and launches various innovative preferential policies; It is the self-innovation of the equity crowdfunding platform in the process of business development. The first-timers will drive the latecomers to improve the equity crowdfunding ecology.

\section{Suggestions on the Combination of Crowdfunding and Technological SMEs}

Technology-based SMEs should make full use of the Internet crowdfunding platform to grow and develop. Specifically, technology-based SMEs should further improve their technological innovation capabilities, in particular, the degree of consumer recognition of innovative products, attract public attention and investment enthusiasm; choose a crowd-raising platform with good reputation and high credibility to increase the success rate of crowdfunding Try to show their own business scope and business content, make their own information transparent and transparent; make transparent use of the use of funds and methods, so that investors can immediately understand the whereabouts of tracking funds; improve awareness of intellectual property protection, prevent project ideas in It was imitated and plagiarized during the exhibition.

The Crowdfunding Model will be introduced into the government market decision-making mechanism. Support for market-accepted technology innovation projects on crowdfunding platforms. It is recommended that government departments in charge of science and technology should introduce a market decision mechanism in the crowdfunding model. When supporting market-oriented application of technological innovation projects, the blind assessment model should be used to allow more users of technology innovation projects such as consumers and consumers to use the market. The technical innovation projects to be supported are evaluated. The more the number of market users, the better, and the technological innovation projects supported by most market users can be used as the reference for the government to support the decision-making of the technological innovation project, and promote the development of more technological innovation projects for the market. Work, promote scientific and technological work to better face the main battlefield of the economy, and give play to the role of science and technology in leading economic and social development.

Building a Scientific and Technology Crowdfunding Platform to Create a New Environment of "Popular Innovation, People's Entrepreneurship". In the new era of innovation leading the new normal economic development, it is recommended that the government's scientific and technical authorities should set up a platform for scientific and technological crowd-funding to build channels and paths to promote "mass innovation and innovation" and try to adopt a crowdfunding model to support scientific and technological projects and break through conventional technology projects. Support forms to allow more and better creative and innovative projects, new technologies and new products, and innovative entrepreneurs to demonstrate and interface with the technology innovation crowdfunding platform, and interact with more innovative entrepreneurs, investors, consumers and other people, Get more funding, channels, wisdom and other resources to support the promotion of new technologies and new products better and faster in the market promotion and application, and strive to create a "mass innovation, innovation and entrepreneurship," a new environment.

Drawing on the crowdfunding model to promote the construction of new technology incubators that provide integrated services for the entire chain of innovation and entrepreneurship. Crowdfunding is used as a mode and mechanism to provide innovative and comprehensive services for innovative entrepreneurs, and a comprehensive service-type incubator is constructed to meet the needs of innovation and entrepreneurship. The transition from incubator services such as venues, registrations, taxation, and policies to a single incubator is required. Mass community innovation, comprehensive services such as venture capital investment, media promotion, market channel construction, innovative creative market interaction, upgrading of technology incubator service functions, continuous improvement of existing technology incubator functions, and construction of a number of innovative and entrepreneurial whole chains for key areas The new technology incubator for comprehensive services provides a low-cost, convenient, and full-featured open integrated service 
platform for the growth of micro-innovation companies and personal entrepreneurship to better serve the innovation and entrepreneurial activities of companies and individuals.

\section{References}

[1] Information on http://www.zhongchoujia.com/data/30765.html

[2] Information on https://www.wdzj.com/news/yc/2245778.html

[3] Information on http://www.ca-sme.org/content/Content/index/id/14632

[4] Berger A N, Udell G F. The economics of small business finance: The roles of private equity and debt markets in the financial growth cycle[J]. Journal of banking \& finance, 1998, 22(6-8): 613-673.

[5] M. Zhu, C. Zhang. Research on financing difficulties for SMEs[J]: Operations and Management, (2016) No.11, p.63-65.(In Chinese)

[6] Y. Guo. Technology SME financing difficulties and credit rationing behavior of commercial banks [J]: Economic Issues, (2007) No.7, p.109-111.(In Chinese)

[7] P. Xie, C.W. Zou and H.Y. Liu.Research on Internet Financial Model [J]: Financial Research, (2012) No.12, p.1.(In Chinese)

[8] W.B. Fan.China's Equity Crowdfunding Development Proposal under the New Normal Economy: A Perspective of Financing Matching and Institutional Environment [J]: New Finance, (2016) No.4, p.38-41.(In Chinese)

[9] J. Wan.Looking forward to the "turning overtaking" of the Internet finance industry - Interpretation of "Guiding Opinions on Promoting the Healthy Development of Internet Finance" [J]: Banker, (2015) No.8, p.20-21.(In Chinese)

[10] Z.R. Sun, P. Shi.Industrial Clusters and Regional Economic Development [J]: Economic Research Reference, (2006) No.7, p.202-203.(In Chinese)

[11] Information on https://www.sohu.com/a/230816135_530780

[12] S.Z. Gu, M. Yang and Q.Q. Chong.The Strategic Thinking of Regulating the Development of Equity Crowdfunding to Support Venture Innovation[J]: Economic Review, (2016) No.7, p.7-12.(In Chinese)

[13] Gans J, King S, Stonecash R, et al: Principles of Economics (Cengage Learning, 2011).

[14] Ackerloff G. The market for lemons: Quality uncertainty and the market mechanism[J]. Quarterly journal of economics, (1970) No.84, p.488-500.

[14] D. Yang, Y.X. Huang.China-style equity crowdfunding development suggestions [J]: China Finance, (2015) No.3, p.63-66.(In Chinese)

[15] Z.J. Liu.Equity Crowdfunding: Development Foundation and Reality Barriers [J]: Banker, (2015) No.12, p.77-80.(In Chinese)

[16] H.F. Peng, H.Y. Zhao. "Hot development" and "Cold thinking" of Chinese equity crowdfunding based on the new regulatory framework[J]: Research on Financial Development, (2016) No.7, p.31-37.(In Chinese)

[17] Y.B. Ma.The Reality and Development Path of Market Withdrawal Mechanism of Equity Crowdfunding Industry[J]: Financial Theory and Practice, (2016) No.11, p.74-78.(In Chinese) 